канд. техн. наук Болибрух Б.B. / Bolibrukh B.V., Ph.D. ${ }^{1}$

канд. техн. наук М. Хмель / M. Chmiel, Ph.D. ${ }^{2}$

\title{
Разработка и верификация расчетной модели теплового состояния теплозащитной одежды пожарного при различных видах испытаний
}

\author{
Development and Verification of a Mathematical Model Dealing \\ with Thermal Protective Garments for Different Types of Tests
}

\author{
Opracowanie i weryfikacja modelu cieplnego ubrania strażackiego \\ chroniącego przed czynnikami termicznymi dla różnych rodzajów badań
}

\begin{abstract}
АННОТАЦИЯ
Введение: Работа пожарного при тушении пожаров сопряжена с большим риском для жизни и здоровья. Тепловое воздействие и физические нагрузки при этом часто граничат с предельными уровнями для человека и материалов теплозащитной одежды или превышают их. Так, материал теплозащитной одежды пожарного (ТЗОП) может перегреваться либо прожигаться, что может вызвать возникновение ожогов. Повышение температуры в подкостюмном пространстве может привести также к тепловому удару. Для увеличения безопасности работы крайне важно знать предельное безопасное время работы пожарного (ПВРП) в тех или иных условиях тушения пожаров и не допустить его превышения.

Цель: Целью является разработка и верификация расчетных тепловых моделей теплозащитной одежды пожарного в различных условиях тепловых испытаний для прогнозирования и анализа теплового состояния и определения предельного времени работы пожарного в такой теплозащитной одежде.

Методы: Существует ряд методов и установок для экспериментальных исследований защитных свойств одежды, в которых испытываемый образец подвергается тепловой нагрузке от различных источников теплоты. Поскольку натурные испытания представляют собой достаточно сложную и дорогостоящую процедуру, то в настоящее время при проектировании теплозащитной одежды пожарных все больше используется метод моделирования теплового состояния теплозащитной одежды без или совместно с телом пожарного. Моделирование за счет своей оперативности дает возможность анализировать большее количество условий работы пожарного, а также факторов влияющих на тепловое состояние ТЗОП. Моделирование позволяет проводить многократные расчеты теплового состояния для различных материалов ТЗОП в поисках оптимального сочетания слоев материалов с наилучшими теплозащитными свойствами при наименьшем весе и цене.

Результаты: Разработанные модели могут быть использованы для определения предельного времени работы пожарного, анализа степени влияния различных факторов на тепловое состояние теплозащитной одежды и пожарного, а также могут помочь при разработке новой теплозащитной одежды с применением других материалов.

Выводы: Проведен анализ существующих работ по моделированию теплового состояния защитной одежды пожарного, который показал необходимость их усовершенствования для применения в различных условиях воздействия опасных факторов пожара. Разработана и по данным тепловых испытаний проверена расчетная модель теплового состояния трехслойной теплозащитной одежды пожарного в условиях теплового испытания. Разработанная модель может быть применена для определении оптимальных параметров защитного костюма и определения предельного времени работы пожарного в различных условиях тушения пожаров.
\end{abstract}

Ключевые слова: теплозащитная одежда пожарного, тепловые испытания одежды, моделирование, предельное время работы пожарного

Вид статьи: оригинальная научная статья

\footnotetext{
1 Львовский государственный университет безопасности жизнедеятельности / Lviv State University of Life Safety;. bolibrykh@ukr.net; вклад в создание статьи / percentage contribution - 70\%;

2 Центральная школа Государственной пожарной службы Республики Польша / Central School of the State Fire Service in Częstochowa, Poland; вклад в создание статьи / percentage contribution - 30\%;
} 


\section{A BSTRACT}

Introduction: The work of a firefighter, during fire incidents, is fraught with significant health risks and potential for loss of life. Often, such work results in exposure to heat bordering on acceptable limits of endurance for humans and exceeding norms for materials used in the manufacture of thermal protective clothing. Materials used in the manufacture of protective clothing may overheat or catch fire and cause burns. An excessive temperature increase for humans may also cause heat stroke. In order to increase the safety of a firefighter, it is important to establish a safe working period, for specific operational conditions, and not permit for such limits to be exceeded.

Aim: The purpose of this treatise is to develop and verify mathematical models dealing with thermal properties of firefighter's protective clothing, for different tests conditions, with the view of predicting and analyzing thermal conditions as well as determining maximum operating periods for firefighters equipped with such clothing.

Methods: There are a number of methods and experimental study approaches to determine the properties of protective clothing, in which test samples are exposed to heat from different sources. Because full-scale tests are quite complicated and expensive, consequently, at the design stage, an increasingly frequent use is made of thermal mathematical models with or without the participation of a firefighter. Modelling, because of its operability, allows for an analysis of a larger volume of working conditions as well as influences on the temperature of protective clothing. Modelling facilitates numerous thermal calculations for different materials used in manufacture of protective clothing with the purpose of identifying an optimal link between appropriate layers of materials used and best thermal protection whilst achieving the least weight for the garment and lowest production cost.

Results: Developed mathematical models can be used to determine maximum operating periods for firefighters. They facilitate an analysis of the degree of influence, for a range of factors, on the physical condition of a firefighter as well as that of clothing which should protect from the effects of heat. Such models may also help in the development of new manufacturing technology with use of other materials. Conclusion: An analysis of accessible projects engaged with modelling of thermal protective clothing properties revealed the need to improve modelling methods so that an application may be found for different fire hazard conditions. Developed, in compliance with data for thermal studies, and tested the mathematical model for determining the thermal condition of a three layered protective garment in a thermal test environment. The developed model can be used to determine the optimum parameters for a protective suit and the maximum operating time for a firefighter in different operating circumstances.

Keywords: firefighter's heat resistant clothing, thermal testing of clothing, modelling, firefighter's maximum operating period Type of article: original scientific article

\section{A B S T R A K T}

Wprowadzenie: Praca strażaka podczas działań gaśniczych obciążona jest dużym ryzykiem dla jego życia i zdrowia. Często towarzyszą jej graniczne lub ponadnormowe wartości oddziaływania ciepła i obciążenia fizycznego przyjęte dla organizmu człowieka oraz materiałów odzieży chroniącej przed czynnikami termicznymi. Materiał, z którego wykonane jest ubranie, może ulec przegrzaniu lub zapalić się, powodując oparzenia. Wzrost temperatury pod ubraniem może również doprowadzić do udaru cieplnego. Aby zwiększyć bezpieczeństwo funkcjonariusza straży pożarnej, należy koniecznie określić bezpieczny limit jego czasu pracy dla określonych warunków działań gaśniczych i nie dopuścić do jego przekroczenia.

Cel: Celem artykułu jest opracowanie i weryfikacja obliczeniowych modeli cieplnych ubrania strażackiego chroniącego przed czynnikami termicznymi dla różnych rodzajów badań termicznych w celu prognozowania i analizy warunków termicznych oraz określenia maksymalnego czasu pracy strażaka w ubraniu tego typu.

Metody: Istnieje wiele metod i stanowisk eksperymentalno-badawczych do pomiaru właściwości ochronnych ubrań, w których badana próbka poddawana jest obciążeniu cieplnemu pochodzącemu z różnych źródeł ciepła. O ile badanie w pełnej skali wiąże się z dość skomplikowaną i kosztowną procedurą, w dzisiejszych czasach, przy projektowaniu ubrania chroniącego przed czynnikami termicznymi dla strażaków, coraz częściej wykorzystuje się metodę modelowania cieplnego ubrania bez lub z udziałem ciała strażaka. Modelowanie dzięki swojej operatywności pozwala analizować większą skalę warunków pracy strażaka, jak również czynników wpływających na temperaturę ubrania ochronnego. Modelowanie pozwala na przeprowadzanie wielokrotnych obliczeń stanu cieplnego różnych materiałów ubrania chroniącego przed czynnikami termicznymi, których celem jest znalezienie optymalnego połączenia odpowiednich warstw materiałów i najlepszych właściwości ochronnych przed ciepłem, przy zachowaniu jak najmniejszej wagi i ceny ubrania.

Wyniki: Opracowane modele mogą być wykorzystane do określenia maksymalnego czasu pracy strażaka, analizy stopnia wpływu różnych czynników na stan cieplny strażaka oraz ubrania strażackiego chroniącego przed czynnikami termicznymi i strażaka, a także jako pomoc przy opracowywaniu nowej technologii wytwarzania ubrań tego typu przy wykorzystaniu innych materiałów.

Wnioski: Przeprowadzona analiza dostępnych prac na temat modelowania stanu cieplnego ubrania ochronnego strażaka wykazała konieczność doskonalenia metod modelowania, aby znalazły zastosowanie w różnych warunkach oddziaływania niebezpiecznych czynników pożaru. Opracowano i, zgodnie z danymi na temat badań cieplnych, sprawdzono model obliczeniowy stanu cieplnego trójwarstwowego ubrania strażackiego chroniącego przed czynnikami termicznymi podczas badania termicznego. Opracowany model może być zastosowany do określenia optymalnych parametrów ubrania ochronnego i określenia maksymalnego czasu pracy strażaka w różnych warunkach prowadzonej akcji gaśniczej.

Słowa kluczowe: ubranie ochronne chroniące przed czynnikami termicznymi, badania termiczne ubrania, modelowanie, maksymalny czas pracy strażaka

Typ artykułu: oryginalny artykuł naukowy 


\section{1. Введение}

Работа пожарного при тушении пожаров сопряжена с большим риском для жизни и здоровья. Тепловое воздействие и физические нагрузки при этом часто граничат с предельными уровнями для человека и материалов теплозащитной одежды или превышают их. Так, материал теплозащитной одежды пожарного (ТЗОП) может перегреваться либо прожигаться, что может вызвать возникновение ожогов. При повышении температуры в подкостюмном пространстве, предельное значение которой составляет $50^{\circ} \mathrm{C}$, начинается повышение внутренней температуры тела, увеличение частоты сердечных сокращений и давления, что приводит к нарушению терморегуляции, ухудшению самочувствия и может привести к тепловому удару [1]. Для увеличения безопасности работы крайне важно знать предельное время работы пожарного (ПВРП) в тех или иных условиях тушения пожаров и не допустить его превышения.

На сегодняшний день в мире накоплен большой опыт натурных огневых испытаний материалов теплозащитной одежды, а также разработаны стандарты таких испытаний. Существует ряд методик и установок для экспериментальных исследований защитных свойств одежды (например $[2,3])$, в которых испытываемый образец подвергается тепловой нагрузке от различных источников теплоты. Поскольку натурные испытания представляют собой достаточно сложную и дорогостоящую процедуру, то в настоящее время при проектировании теплозащитной одежды пожарных все больше используется метод моделирования теплового состояния теплозащитной одежды без или совместно с телом пожарного. Моделирование за счет своей оперативности дает возможность анализировать большее количество условий работы пожарного, а также факторов влияющих на тепловое состояние ТЗОП. Моделирование позволяет проводить многократные расчеты теплового состояния для различных материалов ТЗОП в поисках оптимального сочетания слоев материалов с наилучшими теплозащитными свойствами при наименьшем весе и цене.

\section{1. Анализ публикаций}

На сегодняшний день существует достаточно большое количество работ посвященных моделированию теплового состояния теплозащитной одежды. Так, в работе [4] представлены результаты тепловых испытаний и моделирования пакета ТЗОП при воздействии радиационной тепловой нагрузки. Представлены результаты сравнения результатов расчетов температур слоев ТЗОП с результатами тепловых испытаний. Представленные результаты использовались также для верификации и настройки модели, разработанной в рамках настоящей работы. Также, имеются результаты моделирования, проведенного зарубежными учеными. Так, в [5] описано моделирование теплового состояния специально разработанного теплового манекена „Fireman”, одеваемого в теплозащитную одежду и подвергаемого тепловому воздействию огня, которые сравниваются с результатами тепловых испытаний. Однако в приведенной работе представлены результаты краткосрочного теплового воздействия в течение 4 с, что не позволяет в полной мере получить представление о максимальном времени работы пожарного.

Следует отметить, что моделирование не может точно предсказать такие явления как прогорание и разрушение ТЗОП, но хорошо может показывать его тепловое состояние при тепловых нагрузках, не приводящих к таким эффектам. Для адекватной верификации (проверки точности) моделей теплового состояния ТЗОП необходимы данные тепловых испытаний, проведенных в условиях, при которых не наступает прожига или разрушения ТЗОП, при которых велика вероятность перегрева внутренней поверхности теплозащитной одежды и перегрева организма пожарного, либо наступления ожогов или теплового удара.

\section{2. Цель работы}

Целью данной работы является разработка и верификация расчетных тепловых моделей теплозащитной одежды пожарного в различных условиях тепловых испытаний для прогнозирования и анализа теплового состояния и определения предельное время работы пожарного в такой теплозащитной одежде пожарного.

Для достижения указанной цели были выполнены следующие задачи:

1. провести анализ существующих работ по моделированию теплового состояния ТЗОП в различных условиях тепловых испытаний;

2. представить результаты тепловых испытаний фрагмента ТЗОП в соответствии с требованиями украинского и американского стандартов;

3. разработать расчетную модель теплового состояния ТЗОП при выбранных выше условиях испытаний;

4. провести идентификацию недостаточно известных параметров и верификацию модели по результатам выбранных выше испытаний;

5. провести анализ возможного применения разработанной модели для определения оптимальных параметров защитного костюма и предельного времени работы пожарного в различных условиях тушения пожаров по критерию достижения максимальной температуры $50^{\circ} \mathrm{C}$ в подкостюмном пространстве.

Предельное время работы пожарного зависит от характеристик ТЗОП (количество, материал и толщины слоев), интенсивности теплового воздействия и условий работы (температура, влажность и скорость обдува костюма окружающим воздухом), а также интенсивности выполняемых человеком работ. Так, диапазон температур окружающей среды, при которых пожарный выполняет задания, может быть от $-20^{\circ} \mathrm{C}$ и ниже при работе зимой на улице и до $400^{\circ} \mathrm{C}$ и выше в непосредственной близости от пламени. 
При больших внешних тепловых нагрузках первым наступает перегрев внутренней поверхности костюма и подкостюмного пространства. При длительных, но не очень больших тепловых нагрузках и при высокой интенсивности работы перегреться может организм человека, в то время как температура внутренней поверхности костюма может не превысить критического значения $50^{\circ} \mathrm{C}$.

\section{3. Описание объекта исследования}

В работе исследовалась типичная ТЗОП, используемая курсантами Львовского Государственного Университета Безопасности Жизнедеятельности (ЛГУ БЖД) для предоставления им практических рекомендаций по работе в условиях действия пожара. Это ТЗОП является продукцией польской фирмы GO WEST, модель одежды USP 2-2 (рис. 1).
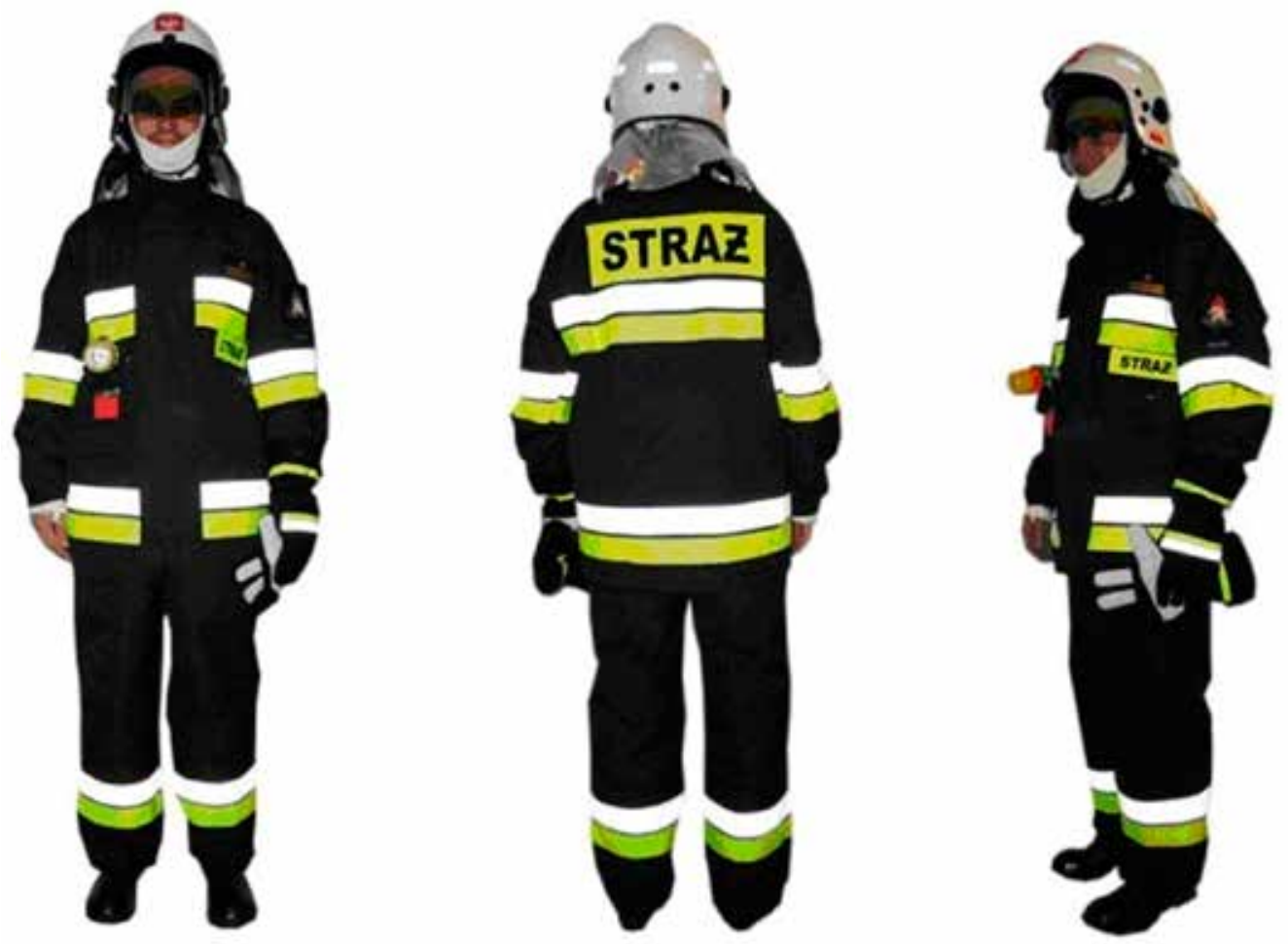

Рис. 1. Теплозащитная одежда пожарного USP 2-2

Fig. 1. Heatproof clothing of a fireman USP 2-2

Источник: Собственная разработка.

Source: Own elaboration.

ТЗОП состоит из куртки и брюк, изготовленных из следующего трехслойного пакета материалов: для наружного слоя 1 (табл.1) используется специальная внешняя ткань Nomex IIIA, в качестве среднего слоя 2 используется неопреновая влагозащитная мембрана, а с внутренней стороны используется слой 3 термоизоляционного материала ARALITE. Толщины и физические характеристики используемых материалов также приведены в табл. 1. Свойства материалов брались из литературы [6], [8-10].

Табл. 1. Геометрические и физические свойства слоев теплозащитной одежды

Table. 1. Geometric and physical properties of the layers of heatproof clothing

\begin{tabular}{|c|c|c|c|c|c|}
\hline $\begin{array}{l}\text { № Слоя/ } \\
\text { Layer } \\
\text { No. }\end{array}$ & $\begin{array}{l}\text { Название и назначение слоя/ } \\
\text { Name and designation of the layer }\end{array}$ & $\begin{array}{l}\text { Толщина, м/ } \\
\text { Thickness, m }\end{array}$ & 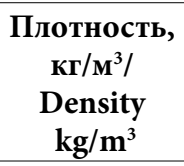 & $\begin{array}{c}\text { Теплоемкость, } \\
\text { Дж/(кг } \times \mathbf{c}) / \\
\text { Heat, } \mathbf{J} /(\mathbf{k g} \times \mathbf{s})\end{array}$ & $\begin{array}{l}\text { Теплопроводность } \\
\text { при } 20^{\circ} \mathrm{C}, \mathrm{Bт} /(\mathrm{M} \times \mathrm{c}) / \\
\text { Thermal conductivity } \\
\text { at } 200^{\circ} \mathrm{C}, \mathrm{W} /(\mathrm{m} \times \mathrm{s}) \\
\end{array}$ \\
\hline 1 & $\begin{array}{c}\text { Bepx }\left(\text { Nomex }^{\circledast} \text { IIIA Pajama Check }\right. \\
\text { Crosstech } \\
\text { ( ) / Top (Nomex }{ }^{\circledast} \text { IIIA } \\
\left.\text { Pajama Check }^{\circledast} \text { Crosstech }^{\circledast}\right)\end{array}$ & 0,00052 & 316,8 & 1300 & 0,047 \\
\hline 2 & $\begin{array}{l}\text { Влагостойкий материал, неопрен } \\
\text { / Waterproof material, neoprene }\end{array}$ & 0,00051 & 800 & 2000 & 0,012 \\
\hline 3 & \begin{tabular}{|c|} 
Теплозащитный слой ARALITE / \\
Heat-shielding layer ARALITE
\end{tabular} & 0,00359 & 74,2 & 700 & 0,036 \\
\hline
\end{tabular}

Источник: Собственная разработка.

Source: Own elaboration. 
Ниже приведены результаты тепловых испытаний фрагмента теплозащитной одежды с применением метода оценки теплозащитных показателей качества ДСТУ ISO 6942-2001 [2]. Схема экспериментальной установки для испытания фрагмента теплозащитной одежды изображена на рис. 2.

В таком виде испытаний фрагмент ТЗОП 3 подвергается фиксированному тепловому потоку от пяти кварцевых ламп, создающих фиксированный тепловой поток, который может меняться для различных испытаний. В рассматриваемом тепловом испытании тепловой поток составлял 2500, Вт/м². Образцы материала ТЗОП размерами 76 × 254 мм размещались в плоскости, параллельной плоскости ламп на расстоянии 25 мм. С не обогреваемой стороны образца размещен калориметр, окруженный тепловой изоляцией. Начало и прекращение теплового воздействия обеспечивается за счет открытия и закрытия заслонки 4. Во время теплового воздействия измеряется температура каждого слоя теплозащитной одежды.

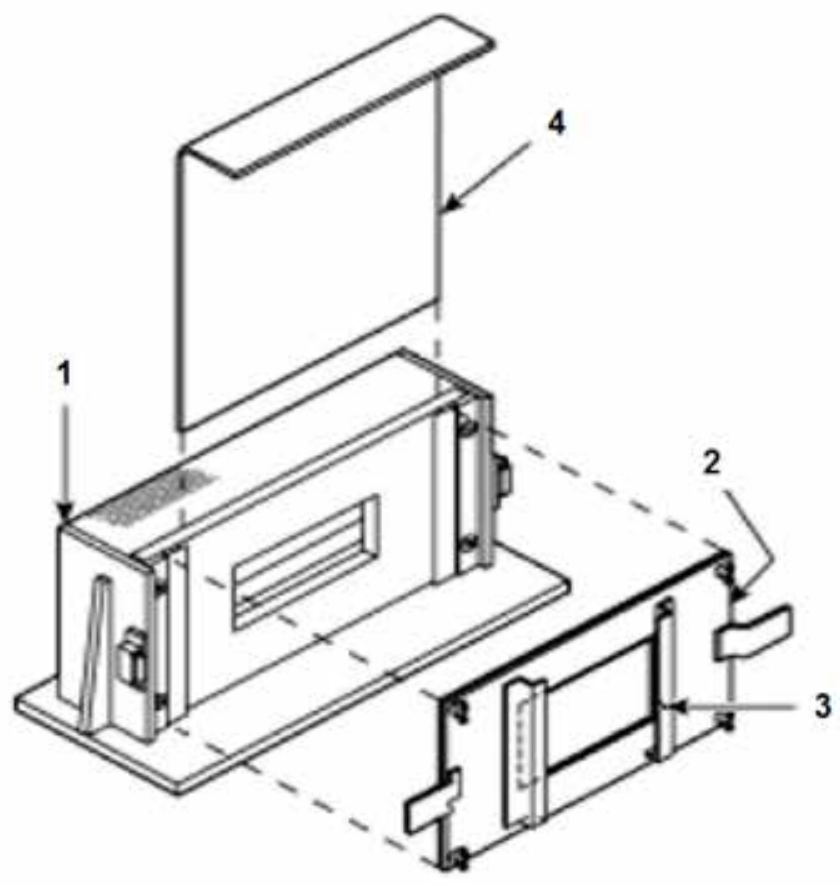

Рис. 2. Схема опытной установки для испытания образцов костюма. 1 - корпус; 2 - крепления; 3 - образец; 4 - заслонка Fig. 2. Scheme of the experimental setup for testing the samples of clothing. 1 - the case; 2 - mounting; 3 - sample; 4 -throttle Источник: Собственная разработка. Source: Own elaboration.

Экспериментальные исследования теплозащитных свойств теплозащитной одежды и теплового комфорта пожарного также проводятся путем тепловых испытаний в специальных симуляционных тренажерах на манекенах, что позволяет избежать угрозы жизни людей в эксперименте и имитировать все основные характеристики пожара. Имеются данные измерений, полученные на тренажере MobileFireTrainer ML2000. Такой тренажер имеет помещение размерами 2 × 2 × 2 м (тренировочную камеру), внутри которого за счет сжигания пропана в горелках создаются условия близкие к реальным условиям пожара.

При испытаниях в тренировочной камере был установлен манекен, одетый в теплозащитную одежду фирмы GO WEST (рис. 1). На внешней и внутренней сторонах ТЗОП в различных местах на манекене установливались термопары, измеряющие температуры во времени с периодичностью 1 с. В результате проведенного теплового испытания были измерены температуры снаружи и в подкостюмном пространстве во времени, по которым построены соответствующие зависимости, приведенные на рис. 5.

\section{2. Методика исследования}

\section{1. Разработка модели для объекта исследования}

Для анализа теплового состояния ТЗОП и определения предельного времени работы пожарного были разработаны модель трехслойного пакета ТЗОП как с учетом калориметра, так и с учетом манекена. Свойства слоев теплозащитной одежды представлены в табл. 1.

Схема теплообмена манекена в пожарном костюме с окружающей средой изображена на рис. 3. Модель учитывает перенос теплоты теплопроводностью внутри слоев костюма, а также конвективный и радиационный теплообмен поверхности пакета ТЗОП с горячими газами окружающей среды.

Учитываются теплопередача через три слоя теплозащитной одежды и воздушные прослойки между ними. В зависимости от моделируемых условий на внутренней поверхности костюма, обращенной к человек, могут быть заданы различные граничные условия. Так, для случая моделирования испытаний пакета (ДСТУ [2]) такими условиями являются условия теплообмена 
через воздушную прослойку с медным калориметром, имеющим начальную температуру $30^{\circ} \mathrm{C}$. Для случая моделирования испытаний, проведенных на манекене, на внутренней поверхности были заданы условия теплообмена через воздушную прослойку с манекеном, который в модели представлен отдельным объемом с соответствующими свойствами.

В модели теплообмен через воздушные прослойки осуществлялся теплопроводностью, излучением и, при необходимости, конвекцией. Свойства воздуха при этом приняты такими: плотность 1,2 кг/м ${ }^{3}$, коэффициент теплопроводности 0,025 Вт/(м × град), теплоемкость 1,0 кДж/кг. Толщина воздушной прослойки между костюмом и человеком или манекеном в реальных условиях может сильно варьироваться от
0 мм до 50 мм. В среднем прослойка имеет толщину 10 мм [5], что и было принято при моделировании.

Для случая моделирования манекена на внешней поверхности теплозащитной одежды имеют место условия конвективно-радиационного теплообмена. Структура и параметры слоев теплозащитной одежды аналогичны модели пакета. Сам манекен моделировался путем добавления в модель дополнительного объема, забирающего на себя часть теплоты с внутренней стороны костюма. Значения теплофизических характеристик манекена были приняты исходя из литературных данных для каучуков следующими: плотность 1100, кг/ $\mathrm{M}^{3}$, коэффициент теплопроводности $0,25, \mathrm{~B}$ /(м × град), теплоемкость 1,2, кДж/кг $[8,9]$.

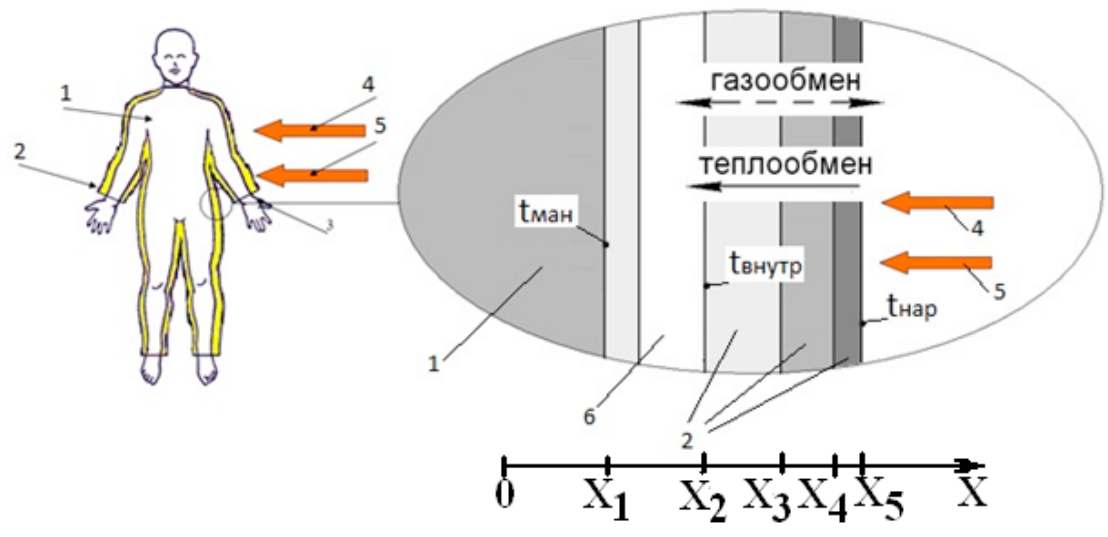

Рис. 3. Схема теплообмена манекена в пожарном костюме с окружающей средой

1 - манекен, 2 - слои ТЗОП, 3 - перчатки защитной одежды, 4 - конвективный и 5 - лучистый тепловые потоки, 6 - воздушная прослойка

Fig. 3. Scheme of heat exchange etween a dummy in the fire suit and the environment

1 - dummy, 2 - layers of heatproof clothing of a fireman, 3 - gloves of the protective clothing, 4 - convection and 5 - radiant heat flux, 6 - air gap

Источник: Собственная разработка.

Source: Own elaboration.

Математическую модель, описывающую теплообмен калориметра (манекена) с окружающей средой через защитный костюм, можно записать, используя одномерное нестационарное уравнение теплопроводности в следующем виде

$c(x, t) \rho(x, t) \frac{\partial t(x, \tau)}{\partial \tau}=\frac{\partial}{\partial x}\left(\lambda(x, t) \frac{\partial t(x, \tau)}{\partial x}\right)$

в области решения (рис.2): для манекена $0<x \leq x_{5}$,

для калориметра $x_{2}<x \leq x_{5}$

с начальным условием $t=t(x, 0)=t_{\text {нач }}$

со следующими граничными условиями:

для манекена

$\frac{\partial t(0, \tau)}{\partial x}=0, \lambda\left(x_{5}, t\right) \frac{\partial t\left(x_{5}, \tau\right)}{\partial x}=q_{\text {конв }}+q_{\text {рад }}$

для калориметра

$\lambda\left(x_{2}, t\right) \frac{\partial t\left(x_{2}, \tau\right)}{\partial x}=c_{\text {кал }} \rho_{\text {кал }} v_{\text {кал }} \frac{\partial t\left(x_{2}, \tau\right)}{\partial \tau}$

$\lambda\left(x_{5}, t\right) \frac{\partial t\left(x_{5}, \tau\right)}{\partial x}=q_{\Sigma}$ где с, $\rho$ и $\lambda$ - теплоемкость, плотность и коэффициент теплопроводности, зависящие от координаты Х и в ряде случаев от температуры $t$ для разных слоев костюма, манекена или калориметра. Для наших условий моделирования 1-й слой принадлежит манекену, 5-й - наружному слою костюма (рис. 2). Для моделирования испытания фрагмента костюма с калориметром слои 1 и 2 отсутствуют.

Начальное распределение температуры (3) всех слоев и объемов модели одинаково и равно начальной температуре $t_{\text {нач}}$, которая для испытания фрагмента костюма с калориметром равна $30^{\circ} \mathrm{C}$, а для испытания манекена в костюме $25^{\circ} \mathrm{C}$.

Тепловой поток на наружной поверхности костюма с координатой $\mathrm{x}_{5}$ и температурой $\mathrm{t}_{\text {пов }}=\mathrm{t}\left(\mathrm{x}_{5}, \tau\right)$ для случая испытания фрагмента костюма с калориметром (5) суммарно включает три составляющие теплового потока

$q_{\Sigma}=q_{\text {нагр }}-q_{\text {конв }}-q_{\text {рад }}$

где $q_{\text {нагр }}$ - тепловой поток падающий от кварцевых радиационных ламп, равный $2500 \mathrm{BT} / \mathrm{M}^{2}, \mathrm{q}_{\text {рад }}$ - радиационный тепловой поток от поверхности фрагмента костюма 
в окружающую температуру $\mathrm{t}_{\mathrm{oc}}=30^{\circ} \mathrm{C}$, вычисляемый по закону Стефана-Больцмана

$q_{\text {рад }}=5.67 \cdot \varphi \cdot \xi \cdot\left(\left(\frac{t_{\text {noв }}+273}{100}\right)^{4}-\left(\frac{t_{o c}+273}{100}\right)^{4}\right)$

$q_{\text {конь }}-$ конвективный поток от поверхности костюма в окружающую среду с той-же температурой, вычисляемый по известной зависимости

$$
q_{\text {конв }}=\alpha\left(t_{\text {пов }}-t_{\text {ос }}\right)
$$

В случае испытания костюма с манекеном радиационная и конвективная составляющие в (4) определяются также по зависимостям (7) и (8), но в качестве температуры окружающей среды $\mathrm{t}_{\text {ос }}$ принимается зависящая температура горячих газов, окружающих костюм.

В (7) $\varphi$ - угловой коэффициент радиационного теплообмена поверхности костюма (принимается 1), $\xi$ - степень черноты этой поверхности, принимаемая равной 0,7 . В (8) а-коэффициент теплоотдачи от горячих газов к поверхности костюма, принимаемый равным 25, Вт/( ${ }^{2}$ K).
На левой границе $\mathrm{x}=\mathrm{x}_{5}$ для случая испытания манекена в костюме принимается граничное условие (4) - условие отсутствия теплообмена, справедливое на достаточной глубине от поверхности манекена,в нашем случае глубине 5 см, т.е. в слое 1 толщиной $0<x \leq x_{1}$ (рис. 2). На этой границе для случая фрагмента костюма с калориметром принимается граничное условие (5) - условие поглощения тепла от внутреннего слоя костюма за счет нагрева высокотеплопроводного

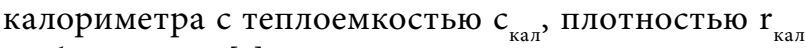
и объемом $\mathrm{v}_{\text {кал }}$ [2].

Математическая модель (1)-(8) интегрировалась численно с помощью устойчивой неявной конечноразностной схемы, учитывающей все особенности и нелинейности модели. Количество узлов численной модели составляло 150.

\section{3. Результаты и их обсуждение}

С помощью разработанной модели были проведены расчеты испытания фрагмента костюма с калориметром, которые затем сравнивались с соответствующими испытаниями согласно [2], приведенными на рис. 4.

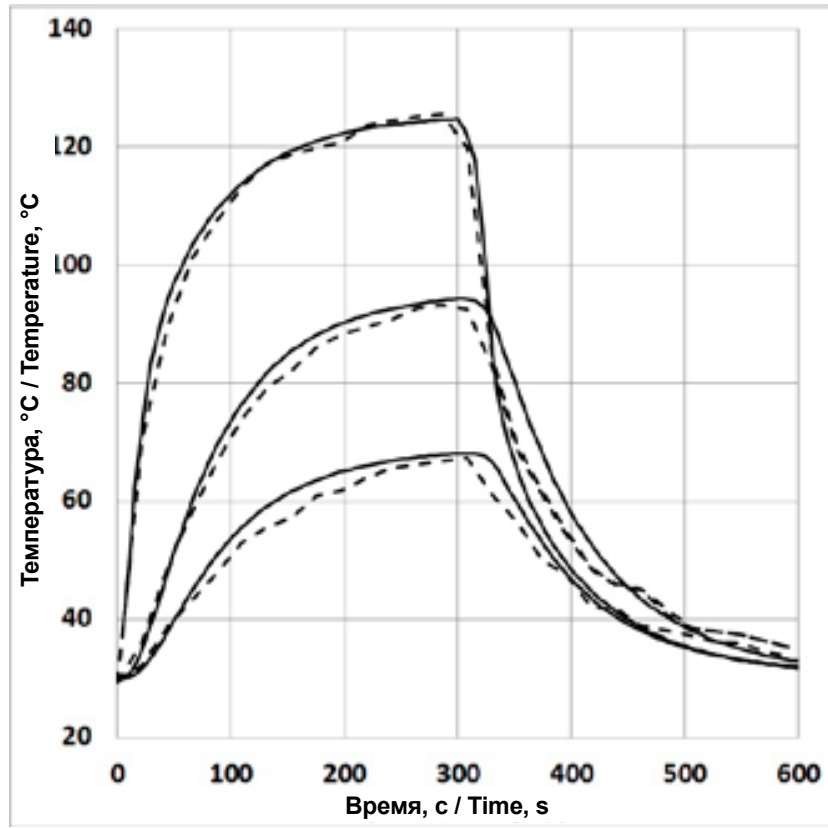

Рис. 4. Зависимость температуры от времени для различных слоев фрагмента ТЗОП. Сплошные кривые - полученные расчетом, пунктирные - результаты измерений по методике [1]. Нижние кривые - для нижнего, средние - для среднего, верхние - для верхнего слоев

Fig. 4. Dependence between temperature and time for different layers of the fragment of heatproof clothing of a fireman. Solid curves - obtained through calculation, dashed - results of measurements carried with the use of the method [1]. Lower curves - for the lower, middle - for the average, top - for the upper layers.

Источник: Собственная разработка. Source: Own elaboration.

Как видно из рисунка расчетные и экспериментальные данные качественно и количественно близки, однако в отдельные моменты времени имеют место отличия измеряемых температур от расчетных до $10^{\circ} \mathrm{C}$. Эти отличия объясняются неточностью задания ряда параметров модели, таких как термические сопротивления воздушных прослоек между слоями, коэффициента теплоотдачи, степени черноты слоев ТЗОП, рассчитанные по приблизительным зависимостям или для которых были приняты допущения. Определенную неточность также вносит неопределенность параметров испытаний. Так, помимо нагрева от ламп, испытываемый образец также находится в конвективном теплообмене с окружающим воздухом, который нагревается от ламп и от самого образца и точная температура которого неизвестна. Модель также не 
учитывает детальное 3-х мерное строение экспериментальной установки (рис. 1), форму калориметра и тепловой изоляции.

Следует отметить, что заданные неточно параметры рассматриваемого образца ТЗОП, несущие в себе неопределенность, могут приводить к достаточно большим отклонениям модельных расчетов от результатов испытаний. Такие параметры образца могут быть уточнены по экспериментальным данным путем их идентификации, после чего настроенная модель может быть использована для последующих расчетов. Такими параметрами в частности являются термические сопротивления зазоров между отдельными слоями ТЗОП и воздушного зазора между ТЗОП и калориметром либо манекеном. Такой подход широко распространен в практике моделирования и носит название расчетно - экспериментального подхода.

Результаты моделирования и тепловых испытаний для данных условий показывают, что предельное время при данной тепловой нагрузке составит около 90-100 секунд по критерию достижения предельной температуры с обратной стороны костюма значения свыше $50^{\circ} \mathrm{C}$. Следует отметить, что полученное время достижения предельной температуры справедливо только для данных конкретных условий испытания и не показывает реального времени работы пожарного при данной тепловой нагрузке так как условия испытания в целом достаточно далеки от реальных условий теплообмена теплозащитной одежды и тела пожарного при реальном пожаре.

Были также проведены расчеты теплового состояния ТЗОП при испытании на манекене, которые затем также сравнивались с соответствующими испытаниями, полученными по методике [3] (рис. 5). Модель манекена в теплозащитной одежде отличалась от модели испытания фрагмента костюма с калориметром тем, что со стороны нагрева задавался не тепловой поток, а конвективно-радиационный теплообмен с окружающей средой, имеющей температуру, значение которой бралось из экспериментальных измерений. Также, моделировался сам манекен, который отбирал на себя теплоту с обратной стороны костюма.

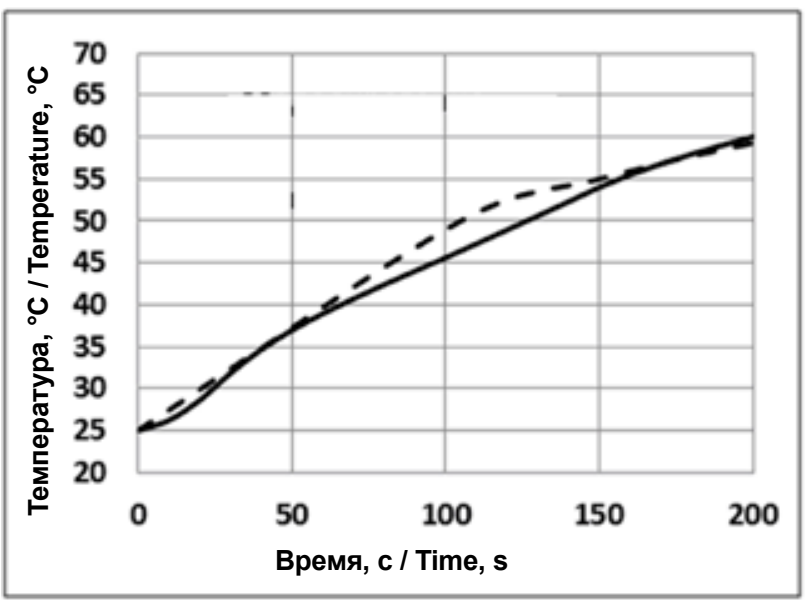

Рис. 5. Зависимость температуры от времени в области грудной клетки манекена (под ТЗОП), полученной при испытании (пунктирная линия) и расчете (сплошная линия) при среднеобъемной температуре в камере $425^{\circ} \mathrm{C}$

Fig. 5. Dependence between temperature and time in the chest area of the dummy (under the heatproof clothing of a fireman) obtained in a test (dashed line) and calculated (solid line) at the average temperature in the chamber at a temperature of $425^{\circ} \mathrm{C}$ Источник: Собственная разработка. Source: Own elaboration.

По результатам испытаний на манекене и данным модельных расчетов предельная температура подкостюмного пространства достигается за время 100-125 с. Из рис. 5 видно, что в отдельные моменты времени расчетная кривая изменения температуры то сближается, то отдаляется от полученной в испытании. Это свидетельствует о том, что модель не учитывает имеющих место в реальности флуктуаций температуры и скорости движения горячего потока воздуха, обтекаемого костюм, и которые в свою очередь приводят к флуктуациям коэффициента теплоотдачи. Движение воздуха в испытании также может приводить к изменению толщины прослойки воздуха между ТЗОП и поверхностью манекена, что может менять условия теплообмена костюма с манекеном. Так, как толщина этой прослойки не известна, то при оценках предельного времени работы пожарного следует пользоваться консервативным подходом используя в расчетах минимальное значение этой толщины.

Таким образом, результаты моделирования теплового состояния теплозащитной одежды пожарного в условиях теплового испытания по украинскому (ДСТУ ISO 6942-2001, где под фрагментом образца одежды находится калориметр), и американскому (NFPA 1001), где под одеждой находится манекен) дают хорошее качественное и количественное совпадение с результатами тепловых испытаний. Разработанные модели также могут быть использованы для определения предельного времени работы пожарного, анализа степени влияния различных факторов на тепловое состояние теплозащитной одежды и пожарного, а также могут помочь при разработке новой теплозащитной одежды с применением других материалов слоев. 


\section{4. Выводы}

1. Проведен анализ существующих работ по моделированию теплового состояния защитной одежды пожарного, который показал необходимость их усовершенствования для применения в различных условиях огневого испытания и тушения пожаров.

2. Разработана и по данным тепловых испытаний проверена расчетная модель теплового состояния трехслойной теплозащитной одежды пожарного в условиях теплового испытания по ДСТУ ISO 69422001и американскому (NFPA 1001). Модель позволяет учитывать детальную структуру теплозащитной одежды и условия тепловых испытаний на установке RPP и тренажере Mobile Fire Trainer ML2000.

3. Разработанная модель может быть применена для определении оптимальных параметров защитного костюма и определения предельного времени работы пожарного в различных условиях тушения пожаров по критерию достижения максимальной

\section{Литература}

[1] Litvinova G.O., Gigiena s osnovamu ekologii, Zdorovya, Kyiv 1999.

[2] Muharovskiy M. (ed.), ДСТУ ISO 6942-2001. Odyag zahisniy teplota vognetrivkiy. otsinyuvannya teploprovidnosti materialiv ta kombinatsiy materialiv, scho zaznayut diyi dzherela teplovogo viprominyuvannya (ISO 6942:1993, IDT), Derzhstandart Ukrayini 2002, IV, 15.

[3] NFPA 1001: Standard for firefighter professional qualifications.

[4] Shtayn B.V., Bolibrukh B.V., Lozinskiy R.Ya., Teoretichne obgruntuvannya poshirennya teploti $v$ paketi materialiv ta povitryanomu prosharku zahisnogo odyagu, "UkrNDITsZ" Vol. 26 Issue 2, 2012, pp. 150-155.

[5] Roger L. Barker, Guowen Song, Hechmi Hamouda, Donald B. Thompson, Andrey Kuznetsov, A. Shawn Deaton, NTC Project: S01-NS02 (formerly I01-S02) National Textile Center Annual Report: November 2002 1Modeling Thermal Protection Outfits for Fire Exposures. температуры $50^{\circ} \mathrm{C}$ в подкостюмном пространстве. По результатам испытаний фрагмента ТЗОП и данным модельных расчетов предельная температура подкостюмного пространства достигается за время 90-100 с. По результатам испытаний на манекене и данным модельных расчетов предельная температура подкостюмного пространства достигается за время 100-125 с.

\section{1.Перспективы дальнейших исследований}

Дальнейшие исследования будут направлены на учет в модели теплового состояния человека в теплозащитной одежде с учетом физиологических особенностей теплообмена и нагрева организма для определения предельного времени работы в условиях повышенных температур по критерию перегрева организма человека. Будет рассмотрено влияние различных условий окружающей среды и интенсивности выполняемой работы на максимальное безопасное время работы пожарного.
[6] Vettori R., Estimates of Thermal Conductivity for Unconditioned and Conditioned Materials Used in Fire Fighters' Protective Clothing, Building and Fire Research Laboratory National Institute of Standards and Technology Gaithersburg, MD 20899-8661, November 2005.

[7] Odyag pozhezhnika zahisniy. Zagalni tehnichni vimogi ta metodi viprobovuvannya (ISO 11613:1999): ДСТУ 4366:2004. [Deystvuyuschiy vid 2005-07-01], Derzhspozhivstandart Ukrayini, 2004, 34 (Natsionalniy standart Ukrayini).

[8] Novichenok N.L., Shulman Z.P., Teplofizicheskie svoystva polimerov, Nauka i tehnika, Minsk 1971, 120.

[9] Babichev A.P., Babushkina N.A., Bratkovskiy A.M. et. al., Fizicheskie velichinyi. Spravochnik, I.S. Grigorev, Meylihov E.Z. (ed.), Energoatomizdat, 1991, 1232.

[10] Kolesnikov P.A., Teplozaschitnyie svoystva odezhdyi, M.: Legkaya industriya, 1965, 346.

Болибрух Борис Васильевич - кандидат технических наук, начальник Главного управления государственной службы Украины по чрезвычайным ситуациям в Хмельницкой области, доцент Львовского государственного университета безопасности жизнедеятельности. Автор более пятидесяти научных работ, разработчик трех национальных стандартов в области пожарной безопасности. Автор пяти учебных пособий, три из которых рекомендованы Министерством образования и науки Украины, автор семи патентов на изобретения, руководитель диссертационных исследований.

Марек Хмель - комендант Центральной школы Государственной пожарной службы в городе Ченстохова. Является кандидатом технических наук в сфере электротехники. Автор и соавтор многих публикаций как государственного, так и международного уровня. Благодаря своей научно-исследовательской деятельности получил множество наград и премий, в том числе: Диплом министра науки и высшего образования во время XIX Ярмарки изобретений (Варшава, март 2012), медаль Комиссии национального образования за особые достижения в образовании и воспитании в июне 2013, премию на Х Международной выставке Edura - Образование и техника службы спасения, в категории Исследовательские проекты 2014. 